Телеп О., Фелака П., Русин М. Комунікація в соціально-культурній сфері ...

УДК 800

DOI https://doi.org/10.24919/2308-4863/34-5-4

\title{
Оксана ТЕЛЕП,
} orcid.org/0000-0001-7924-9121 кандидат наук із соиіальних комунікаиій, заступник директора з навчальної роботи, викладач кафедри сочіокультурної діяльності Ужсгородського інституту культури і мистецтв (Ужгород, Украӥна) о.telep6493-6@uoel.uk

Павло ФЕДАКА, orcid.org/0000-0002-1616-8452 кандидат історичних наук, викладач кафедри сочіокультурної діяльності Ужгородського інституту культури і мистецтв (Ужгород, Україна) fedaka6493-6@unesp.co.uk

Марія РУСИН, orcid.org/0000-0003-1466-9832 студентка кафедри соизікультурної діяльності Ужгородського інституту культури і мистеитв (Ужсгород, Україна) m.rusyn6493-6@murdoch.in

\section{КОМУНІКАЦІЯ В СОЦАЛЬНО-КУЛЬТУРНІЙ СФЕРІ: ОСОБЛИВОСТІ РОЗВИТКУ ТА ТРАНСФОРМАЦІЇ}

У даному науковому дослідженні висвітлюються питання комунікаційної складової частини в умовах сучасного соиіуму та культурній сфері в контексті особливостей ї̈ формування та подальшого розвитку. Звичайно, в умовах сучасного сочіуму комунікаџія відіграє суттєву роль у процесах здобуття інформації окремими індивідами, розвитку їхніх здібностей щзодо формування свого світогляду та вміння якісно будувати відносини зі своїм та чужим оточенням. Крім того, слід зазначити, щуо якісна трансформація комунікаційних стосунків між окремими індивідами сприяє посиленню сочіальних та культурних зв'язків між окремими соціальними прошарками та побудові якісних взаємовідносин між індивідами в умовах сучасного сочіуму. Актуальність заявленоі тематики дослідження зумовлюються наявністю багатьох проблемних питань у сучасній соціально-культурній сфері украӥнського суспільства та необхідністю їх об'єктивного висвітлювання та розв'язання. Методологія даного наукового дослідження має у свойй основі поєднання системного метода дослідження питань, які винесено у його заголовок, та аналізу доступних у рамках вивчення заявленої тематики матеріалів, щзо сприяє найбільш якісному та всебічному розкриттю тематики. Основними результатами, отриманими в ході даного наукового дослідження, слід вважати належну оиінку віртуальних засобів відтворення реальності як нового елемента сучасного комунікаційного простору та констатацію важливості впливу нових технічних засобів комунікації на свідомість суспільства в иілому та окремих його прошарків. Перспективи подальших наукових досліджень у визначеному напрямку полягають у виявленні головних чинників комунікації у соиіально-культурній сфері життя сучасного украӥнського суспільства та якісному вивченні особливостей їхнього впливу на розвиток ситуаціі у сучасному соціумі з точки зору культурних трансформацій та зміџнення стосунків між окремими соціальними прошарками. Прикладна иінність даного наукового дослідження полягає в можливості застосувати на практиці його окремі висновки з метою отримання якісного результату щзодо зміцнення комунікативних зв'язків у сучасному суспільстві між його окремими представниками та певними прошарками соиіуму за умов збереження наявних культурних традицій.

Ключові слова: соиіально-культурна сфера, культурна динаміка, соиіальний розвиток, трансформація соиіальних зв'язків, локальна культура, тендениії розвитку. 
Oksana TELEP,

orcid.org/0000-0001-7924-9121

Candidate of Social Communications,

Deputy Director of Academic Affairs,

Senior Lecturer at the Department of Socio-Cultural Activity

Uzhhorod Institute of Culture and Arts

(Uzhhorod,Ukraine) o.telep6493-6@uoel.uk

Pavlo FEDAKA, orcid.org/0000-0002-1616-8452

Candidate of History,

Senior Lecturer at the Department of Socio-Cultural Activity

Uzhhorod Institute of Culture and Arts

(Uzhhorod, Ukraine)fedaka6493-6@unesp.co.uk

Mariia RUSYN, orcid.org/0000-0003-1466-9832

Student at the Department of Socio-Cultural Activity Uzhhorod Institute of Culture and Arts

(Uzhhorod, Ukraine) m.rusyn6493-6@murdoch.in

\section{COMMUNICATION IN THE SOCIO-CULTURAL SPHERE: FEATURES OF DEVELOPMENT AND TRANSFORMATION}

This study covers the issues of the communication component in the conditions of modern society and cultural sphere in the context of the specific features of its establishment and further development. Admittedly, in the languages of modern society, communication plays a significant role in the processes of obtaining information by individuals, the development of their abilities to shape their worldview and the ability to build relationships within their communities and outside them. In addition, the qualitative transformation of communication relations between individuals contributes to the strengthening of social and cultural ties between certain social strata and the construction of quality relationships between individuals in modern society. The relevance of the subject is conditioned by the presence of many problematic issues in the modern socio-cultural sphere of Ukrainian society and the need for their objective coverage and resolution. The methodology of this study is based on a combination of a systematic method of researching the subject matter, and analysis of available materials on this subject area, which contributes to the most high-quality and comprehensive coverage of the problematics. The main results obtained in this study include an evaluation of virtual means of reproduction of reality as a new element of modern communication space and a statement of the importance of new technical means of communication on the consciousness of society in general and its individual strata. Prospects for further research in this area are to identify the main factors of communication in the socio-cultural sphere of modern Ukrainian society and qualitative study of their impact on the development of the situation in modern society in terms of cultural transformations and strengthening relations between social strata. The applied value of this study lies in the ability to apply its individual conclusions in practice in order to obtain a qualitative result in strengthening communication links in modern society between its members and certain segments of society while maintaining existing cultural traditions.

Key words: socio-cultural sphere, cultural dynamics, social development, transformation of social ties, local culture, development trends.

Постановка проблеми. Комунікація в умовах сучасного соціуму є вельми складним та багатогранним процесом, у якому задіяно багато різноманітних складових. До того ж наявні у сучасній соціально-культурній сфері комунікативні зв'язки між окремими соціальними та культурними прошарками сучасного суспільства зумовлюють необхідність пошуку шляхів щодо їхнього подальшого вдосконалення та розвитку, з оглядом на різноманітність напрямків розвитку загальної культури соціуму на теперішній час. Тому що культурна динаміка $є$ складним, багато- та різ- носпрямованим процесом, що має схильність до впливу на нього безлічі факторів. Ця складність зростає в умовах, коли культурні процеси набувають планетарного масштабу. Проте в цій множині $€$ тенденції, які на певний часовий період стають трендами, що визначають близькі й далекі перспективи культурного буття, спрямованість змін культурної системи (Семилет та ін., 2017: 10). 3 іншого боку, сучасні культури під впливом процесів глобалізації та модернізації різноманітних аспектів суспільного життя починають здебільшого втрачати певні ознаки своєї автентичності. 
Телеп О., Фелака П., Русин М. Комунікація в соціально-культурній сфері ...

Усе більшу актуальність набирає той факт, що сучасні процеси культурної динаміки ведуть до того, що живі організми, здатні до саморозвитку, що поєднують традиції та новації, стійкість та мінливість, переростають у конгломерати різнорідних й різноякісних елементів (Скобелева, 2013: 54). У них розриваються зв'язки $з$ минулим (застарілим та непотрібним), у них втрачається визначеність цілей і ідеалів як проекцій майбутнього, у їх представників формуються ковзаючі, розмиті культурні ідентичності (Семилет та ін., 2017: 13).

Розширенню комунікацій у сучасному соціально-культурному житті активно сприяють новітні досягнення в сучасній науці та техніці, що значно розкривають можливості обміну інформацією та спонукають до переходу на новий рівень комунікативних стосунків в умовах сучасного соціуму. Так, входження в соціальне життя цифрових технологій призвело до появи особливої сфери соціокультурного простору, виникнення в ньому нового рівня - віртуальної реальності. За даними агентства We Are Social та медійної платформи Hootsuite, кількість користувачів Інтернету в 2018 році досягло 4 млрд чоловік, а середньостатистичний користувач мережі Інтернет сьогодні, за даними GlobalWebIndex, проводить у мережі близько 6 годин на день, причому простежується стабільне зростання даних показників із року в рік (Семилет та ін., 2019: 228).

Таким чином, на теперішній час має місце широке розповсюдження нових комунікативних засобів, що сприяють активному збагаченню культури комунікації, але при цього несуть у собі певну небезпеку у зв'язку з можливістю передачі таким чином інформації, що може нести в собі неабияку шкоду для суспільства в цілому та окремих його членів зокрема. Тому визначення особливостей розвитку та вдосконалення наявних на теперішній час засобів сучасної комунікації в соціальнокультурній сфері стає головними чинником розвитку та трансформації інформаційного простору сучасного суспільства та формування можливостей більш якісного його використання 3 точки зору безпеки теперішньої соціальної культури.

Аналіз досліджень. Питання комунікації у сучасній соціально-культурній сфері 3 точки зору їхнього розвитку та подальшої трансформації в певні різновиди активно досліджувалися в наукових роботах Т.А. Семилет, В.В. Вітвинчук, А.Р. Голубевої, І.В. Фотіевої, Е.В. Лукашевич та низки інших авторів. У своїх дослідженнях зазначені автори наголошують на типових закономірностях, що мають місце на певних стадіях розвитку комунікативної системи сучасного суспільства 3 точки зору головних соціальних та культурних закономірностей, що мають суттєвий вплив на особливості формування культурного простору в сучасні часи.

Авторами також висвітлюються численні чинники, що мають місце на різних етапах розвитку теперішнього суспільства та суттєво впливають на комунікативні аспекти взаємодії між окремими його прошарками та членами. Крім того, в дослідженнях згаданих авторів йдеться про різні аспекти розвитку сучасної комунікації у суспільств за рахунок втілення в його життя розмаїття сучасних технологічних винаходів, що також сприяє зміцненню комунікаційної складової частини та появі сучасних можливостей для повноцінного спілкування.

Мета статті полягає у визначенні головних чинників комунікації у сучасній соціально-культурній сфері з точки зору ії подальшого розвитку на трансформації в умовах інформаційного розвитку сучасного суспільства, зміцнення зв'язків між його окремими ланками та формування якісного простору для подальшого розвитку комунікації у сучасному суспільстві та здійснення необхідних трансформацій певних ланок його культурної та інформаційної складової частини.

Виклад основного матеріалу. У XXI столітті мала місце якісна трансформація широкого розмаїття аспектів життя сучасного суспільства, що стало ознакою якісної трансформації соціокультурного життя. Особливо чітко ця трансформація відбилася на пострадянських країнах, на початку нового століття відкрилися світу, й зокрема Заходу. Вплив західноєвропейських країн переоцінити важко - більшість пострадянських республік, включаючи Казахстан, до сих пір активно впроваджують принципи ринкової економіки, нарощують конкурентоспроможність, прагнуть відповідати високим стандартам Європи і Америки. Слідом за провідними розвиненими країнами ми вступили в постіндустріальну фазу розвитку, перейшли від суспільства, націленого на виробництво, до суспільства споживання. Консьюмеризм проник в усі сфери життєдіяльності людини (Бегатинова, Ашилова, 2018: 189).

Сучасне суспільство знаходиться на новому якісному вітку становлення комунікації в різноманітних ланках його життя: соціальній, культурній, освітній тощо. Це вимагає від усіх членів сучасного суспільства нового розуміння процесів, що мають місце на теперішньому етапі його розвитку, та відповідного ставлення до них. Це не лише слова, а й сувора необхідність, бо зміни в культурі сучасного соціуму, зумовлені особливостями роз- 
витку системи комунікації між його різними ланками, відбуваються дуже швидко. Сьогодні можна побачити, як політика перетворюється на змагання іміджів політиків, їхніх образів, симулюється політична діяльність; політичні партії перетворюються з виразників інтересів певних соціальних верств у бренди, під якими декларуються програми з локальними і глобальними проблемами, а реальною основою об'єднання громадян виступає образ того чи іншого політика. Фахівці констатують верховенство віртуальної реальності для здійснення політики: «У сучасному інформаційному суспільстві відбулася трансформація системи представництва цивільних інтересів, результатом якої стало перетворення комунікації в системоутворюючий елемент демократії, в інструмент іiі формування та самопрезентації. Це, у свою чергу, тягне за собою подальшу віртуалізацію політичного простору, перенесення політики і здійснюваних нею функцій зі сфери реальному житті в область «мережевого світу» Інтернету» (Семилет та ін., 2017: 14).

Найважливішим чинником комунікації та засобом комунікативної структури сучасного суспільства, що накладає суттєвий відбиток на усі сфери суспільного життя та культуру соціуму, є мережа Інтернет. Згідно $з$ даними останніх статистичних досліджень саме Інтернет $€$ сферою, що найбільш інтенсивно розвивається 3 точки зору залучення нових користувачів та встановлення нових стандартів зв'язку. Відбувається активна віртуалізація соціальної сфери, про що свідчать розширення сфери дистанційної освіти, віртуальна діагностика, рецептура та консалтинг в медицині. Віртуальними стають музеї, виставки, екскурсії, туризм. Засоби масової комунікації все більшою мірою переміщуються в Інтернет-простір. Віртуальною стають дружба, знайомства, залицяння та багато іншого.

Віртуальна реальність поступово набуває статусу первинності по відношенню до реальної, а маніпуляції зі знаками речей замінюють дії із самими речами (Семилет та ін., 2017: 14). Такі трансформації соціально-культурного середовища не можуть не позначитися на якості сучасного інформаційного обміну, що являє собою складову основу будь-якої інформаційної системи. Сучасна освітня система все частіше вдається до втілення засобів електронної комунікації, організації дистанційного навчання, що передбачає використання сучасних технічних засобів проведення вебінарів, онлайн-конференцій, методик дистанційного зберігання інформації тощо. Особливо це було помітно під час введення суспільних обме- жень, викликаних пандемією коронавірусу, коли майже всі навчальні заклади різних ступенів були змушені здійснити перехід на дистанційну форму навчання. Усі ці нововведення суттєво змінюють структуру сучасної комунікаційної системи та формують новий освітній простір, зі своїми особливостями та властивостями, щодо принципів здійснення комунікації на різних етапах навчання та подальшого розвитку та структурної трансформації комунікаційної системи, що склалася. У контексті формування нового комунікаційного простору в освітній системі слід зупинитися на різноманітних аспектах створення сучасних медійних систем як нових засобів трансформації освітньої системи.

Звичайно, для людського сприйняття характерно відображення предметів та явищ дійсності не тільки безпосередньо, а й опосередковано, за допомогою «знаків», у ролі яких можуть виступати різні символи, сигнали, так звані елементи зображення, що знаходять своє місце і вживання в найбільш універсальній знаковій системі мові. За допомогою слова (сказаного або написаного) люди передають i сприймають різні ознаки та властивості предметів та явищ, оперують їхніми назвами, поняттями тощо.

Чільною рисою медіадискурсу представляється наявність у ньому одночасно зі словесною (мовною) знаковою системою інших семіотичних систем: візуальної, аудіальної. Має місце поєднання образної мови кількох мистецтв (театрального, кінематографічного, музичного та ін.) в їх взаємодії. Власне, це й дозволило свого часу М.С. Кагану (1972: 388-389) віднести електронні види мас-медіа (телебачення та радіомовлення) до «складних синтетичних мистецтв технічного комплексу з образотворчої домінантою».

Складність процесу створення (підготовки) та відтворення медійних текстів $є$ результатом одночасної дії та взаємної адаптації в ході цього процесу знаків різних семіотичних систем і визначається впливом двох істотних чинників: норм побудови тексту (або дискурсу) масової комунікації, які визначаються специфікою каналу та його творцями; об'єктивних семіотичних умов функціонування текстів (смислів) в метадискурсі масмедіа (Суська, 2019: 421-422).

У нинішні часи, аналізуючи тенденції розвитку сучасної культури, неможливо обійти тему різних суперечливих соціальних процесів та явищ. Крім того, важко переоцінити досить дискусійну проблематику, що розгорнулася навколо технічних інновацій, що провокують і прискорюють різні трансформації в інформаційному суспільстві. 
Телеп О., Фелака П., Русин М. Комунікація в соціально-культурній сфері ...

3 одного боку, сучасні засоби комунікації є специфічним індикатором і репрезентантом нових соціальних явищ. 3 іншого боку, сучасні засоби комунікації стають чинним суб'єктом культурних та соціальних трансформацій. Вторгаючись у сферу індивідуального, стаючи найближчим оточенням людини і їі буття, комунікаційні та інформаційні технології дійсно трансформують не тільки самі кордони приватного, сценарій їх об’єктивації, а й істотно трансформують медійну культуру інформаційного суспільства в цілому (Пряхіна, 2018: 80).

Сьогодні процес віртуалізації різноманітних явищ суспільного життя набуває все більших масштабів та має глибокий вплив на практично усі аспекти сьогодення. Комунікація в соціально-культурній сфері з урахуванням впливу процесів віртуалізації інформаційних потоків, що активно споживаються членами сучасного соціуму, набуває нових трансформаційних форм та активно розвивається в певному напрямку. Вчені-фізики ж віртуальність позначають як щось подібне умовному початку, що формально вважається реальним. Технології засобів медійної масової культури, особливо телебачення, та комп'ютерні технології трансформували таке розуміння віртуальності. Сьогодні віртуальне протиставлено фізичному, однак йому привласнений статус реального (Пряхіна, 2018: 80).

У даному контексті впливу віртуальної реальності на різні сфери суспільного життя слід зазначити, що подальша трансформація комунікативної сфери у соціально-культурному житті суспільства має відбуватися в різноманітних формах безконтактного спілкування між окремими членами соціуму та його прошарками. Сучасний світ багато в чому визначається комунікативним та інформаційним простором, створюваним інститутом мас-медіа. Мас-медійні продукти справляють істотний вплив на суспільну свідомість та вельми специфічно впливають на людину зокрема та суспільство загалом. Створювані засобами масової інформації образи, символи і знаки не лише $€$ засобом формування особливостей сприйняття соціальних фактів та певних процесів, а й стають засобом, «ключем» для пізнання сучасної реальності, а деколи й можуть виступати також у ролі самої реальності (Бешукова, 2008: 57).

Циркуляція інформаційних потоків сьогодні настільки швидка та велика й незупинна, що людина перетворюється лише в реципієнта: вона не встигає глибоко оволодівати інформацією, що надходить, аналізувати іiі та поверхнево «схоплює» образи й окремі символи, нескінченно вноситься медійними каналами (Водопьян, 2017: 185). Людина в результаті майже «розчи- няється» в комунікативному просторі та потоках інформації, надаючи тим самим можливість маніпулювати своєю свідомістю. Парадокс нашого часу: маніпулює людиною або групою чи спільнотою людей не інший чоловік або інше співтовариство, а потужно та добре структурована сила масмедіа за допомогою створюваних інформаційних продуктів (Чистяков, 2013: 174).

Тому на теперішній час $є$ вельми важливим визнання факту суттєвого змінення особливостей комунікаційної культури в сучасному світі, що $\epsilon$ невід'ємним чинником зумовлення іiї подальшого розвитку та вдосконалення. Подальші дослідження основ комунікації у сучасному соціумі мають відбуватися з урахуванням нових поступових змін у соціально-культурній сфері та мають дати відповідь на численні питання, що виникатимуть у зв'язку з удосконаленням сучасної системи соціальної та культурної комунікації та розвитком та вдосконаленням самого суспільства.

Висновки. Сучасна масова комунікація має свої характерні ознаки, такі як передача повідомлень різного ступеня складності, адресованих широкій та різноманітній аудиторії та здатних викликати в неї неабиякий інтерес та широку хвилю обговорень. Подібні повідомлення розповсюджуються засобами масової інформації, які в умовах сьогодення представлені у широкому розмаїтті газет, журналів, радіо, кіно- та мульті-медіа, а також безлічі Інтернет-ресурсів. У своїй сукупності ці засоби масової інформації та комунікації докорінно змінили життя суспільства.

Саме феномен сучасної медійної культури $\epsilon$ таким, що без нього не може йтися про розвиток сучасного інформаційного суспільства в контексті аналізу рівня його комунікативної активності. Сучасна медійна культура включає в себе культуру передачі інформації та культуру іiї подальшого сприйняття як окремими особистостями, так і групами індивідів, також вона може виступати й системою рівнів розвитку особистості, здатної читати, аналізувати, оцінювати медіатекст, займатися медіатворчістю, засвоювати нові знання за допомогою медіа тощо.

У сучасному інформаційному світі велике значення має здатність швидко оцінювати нову інформацію що поступає, та приймати рішення на основі отриманої інформації. Тому в умовах сьогодення найважливішим чинником $є$ здатність окремих індивідів та їхніх груп до втілення нових комунікаційних шляхів, побудованих 3 урахуванням тенденцій, що мають місце у сучасному медіа-просторі, та швидко адаптуватися до мінливих умов сьогодення. Без цього немає мож- 
ливості вести мову щодо розвитку комунікації у сучасному соціально-культурному середовищі та якісно оцінювати можливі трансформаційні форми цього процесу в майбутньому.

\section{СПИСОК ВИКОРИСТАНИХ ДЖЕРЕЛ}

1. Бегатинова К. К., Ашилова М. С. Влияние общества потребления на систему образования. Вестник Новосибирского государственного педагогического университета. 2018. № 2. С. 189-202.

2. Бешукова Ф. Б. Медиадискурс современного культурного пространства. Вестник Адыгейского государственного университета. Серия 2: Филология и искусствоведение. 2008. № 5. С. 52-58.

3. Водопьян В. Г. Медиа-пространство в сфере массовой коммуникации: социокультурная реальность. Вестник Адыгейского государственного университета. Серия 1: Регионоведение: философия, история, соииология, юриспрудениия, политология, культурология. 2017. № 1(194). С. 182-189.

4. Каган М. С. Морфология искусства. Историко-теоретическое исследование внутреннего строения мира искусств. Москва : Искусство, 1972. 440 с.

5. Пряхіна А. В. Нові технічні засоби комунікації у трансформації медійної культури інформаційного суспільства. Знак: Проблемне поле медіаосвіти. 2018. № 2. С. 80-85.

6. Семилет Т. А., Вітвинчук В. В., Голубева А. Р. Тренди та перспективи сучасної культурної динаміки. Філософія та культура. 2017. № 11. С. 10-20.

7. Семилет Т. А., Вітвинчук В. В., Фотіева І. В., Лукашевич Е. В. Соціальні мережі як культурні матриці інтернеткомунікації. Культура й текст. 2019. № 3(38). С. 226-242.

8. Скобелева Е. И. Коммуникативные аспекты конструирования социокультурного пространства города. Вестник Нижегородского университета им. Н. И. Лобачевского. Серия: Социальныле науки. 2013. № 2(30). С. 53-59.

9. Суська О. А. Видозміна досліджень медіадискурс в фокусі міждисциплінарності. Комунікативні дослідження. 2019. № 2. С. 420-434.

10. Чистяков Д. И. Информационное общество и СМИ в коммуникативном пространстве пост современности. Вестник Российского университета дружбы народов. Серия: Философия. 2013. № 2. С. 173-179.

\section{REFERENCES}

1. Begatinova K. K., Ashilova M. S. Vliyaniye obshchestva potrebleniya na sistemu obrazovaniya [The influence of consumer society on the education system]. Bulletin of Novosibirsk State Pedagogical University, 2018, Nr 2, pp. 189-202 [in Russian].

2. Beshukova F. B. Mediadiskurs sovremennogo kulturnogo prostranstva [Media discourse of modern cultural space]. Bulletin of the Adyghe State University. Series 2: Philology and Art Criticism, 2008, Nr 5, p. 52-58 [in Russian].

3. Chistyakov D. I. Informatsionnoye obshchestvo i SMI v kommunikativnom prostranstve post sovremennosti [Information society and the media in the post-modern communicative space]. Bulletin of the Peoples' Friendship University of Russia. Series: Philosophy, 2013, Nr 2, p. 173-179 [in Russian].

4. Kagan M. S. Morfologiya iskusstva. Istoriko-teoreticheskoye issledovaniye vnutrennego stroyeniya mira iskusstv [Morphology of art. Historical and theoretical study of the inner structure of the art world]. M.: Iskusstvo, 1972.440 p. [in Russian].

5. Pryakhina A. V. Novi tekhnichni zasoby komunikatsiyi u transformatsiyi mediynoyi kultury informatsiynoho suspilstva [New technical means of communication in the transformation of media culture of the information society]. Sign: Problem Field of Media Education, 2018, Nr 2, p. 80-85 [in Ukrainian].

6. Semilet T. A., Vitvinchuk V. V., Fotieva I. V., Lukashevich E. V. Sotsialni merezhi yak kulturni matrytsi internet-komunikatsiyi [Social networks as cultural matrices of Internet communication]. Culture and Text, 2019, Nr 3 (38), pp. 226-242 [in Ukrainian].

7. Semilet T. A., Vitvinchuk V. V., Golubeva A. R. Trendy ta perspektyvy suchasnoyi kulturnoyi dynamiky [Trends and prospects of modern cultural dynamics]. Philosophy and Culture, 2017, $\mathrm{Nr}$ 11, pp. 10-20 [in Ukrainian].

8. Skobeleva E. I. Kommunikativnyye aspekty konstruirovaniya sotsiokulturnogo prostranstva goroda [Communicative aspects of constructing the socio-cultural space of the city]. Bulletin of the Nizhny Novgorod University named after N. I. Lobachevsky. Series: Social Sciences, 2013, Nr 2 (30), pp. 53-59 [in Russian].

9. Suska O. A. Vydozmina doslidzhen mediadyskurs v fokusi mizhdystsyplinarnosti [Modification of research media discourse in the focus of interdisciplinarity]. Communicative Research, 2019, Nr 2, pp. 420-434 [in Ukrainian].

10. Vodopyan V. G. Media-prostranstvo v sfere massovoy kommunikatsii: Sotsiokulturnaya realnost [Media space in the field of mass communication: Socio-cultural reality]. Bulletin of the Adyghe State University. Series 1: Regional Studies: Philosophy, History, Sociology, Jurisprudence, Political Science, Culturology, 2017, Nr 1 (194), p. $182-189$ [in Russian]. 